\title{
Iron deficiency as an emerging therapeutic target in patients stabilized after an episode of acute heart failure
}

\author{
Michał Tkaczyszyn ${ }^{1,2}$, Tomasz Skrzypczak ${ }^{3}$, Jakub Michałowicz ${ }^{3}$, \\ Piotr Ponikowski ${ }^{1,2}$, Ewa A. Jankowska, ${ }^{1,2}$ \\ ${ }^{1}$ Institute of Heart Diseases, Wroclaw Medical University, Wroclaw, Poland \\ ${ }^{2}$ Institute of Heart Diseases, University Hospital, Wroclaw, Poland \\ ${ }^{3}$ Faculty of Medicine, Wroclaw Medical University, Wroclaw, Poland
}

\begin{abstract}
Acute heart failure (AHF) syndromes are among the most frequent causes of hospitalization in the elderly and put a heavy financial burden on healthcare systems, mainly due to high early readmission rates. The understanding of AHF has evolved over the years from a significant hemodynamic failure to a multi-organ disease in the course of which peripheral mechanisms such as dysregulated cardiorenal axis or inflammation also play essential roles. A few available observational studies investigating iron deficiency (ID) in patients hospitalized for AHF indicate that this comorbidity is more prevalent than in chronic heart failure, and iron status presents some dynamics in these subjects. ID in AHF predicts increased mortality, greater risk for early readmission and is related to prolonged hospitalization. This paper reviews the results of the first multicenter, double-blind, randomized clinical trial on ferric carboxymaltose in patients who were stabilized after an episode of AHF who had concomitant ID (AFFIRM-AHF), and potential pathophysiological links between dysregulated iron status and AHF syndromes are discussed. (Cardiol J 2021; 28, 6: 962-969)
\end{abstract}

Key words: acute heart failure, cardiac decompensation, iron deficiency, ferric carboxymaltose

\section{Introduction}

Acute heart failure (AHF) syndromes constitute one of the most frequent causes of hospitalization in the elderly and, analyzed in total, put a heavy financial burden on healthcare systems in developed countries [1-4]. Importantly, 30-day readmission rates exceed $25 \%$ in this patient population and it has been demonstrated that among these frequent early re-hospitalizations, a significant proportion will also be due to heart failure (HF) (recurrent episodes) [5]. From a clinical perspective, hospitalization due to AHF should always be considered a highly important adverse health event because such an episode represents the "inflection point" [6] in the natural history of the disease. The perception of AHF (in both observational and interventional trials overrepresented by the form of decompensation of pre-existing or de novo heart failure - $\mathrm{ADHF}$ ) has evolved over the years from a hemodynamic failure (most frequently with fluid overload/congestion) to a multi-organ disease during which peripheral mechanisms such as dysregulated cardiorenal axis (acute "cardiorenal syndrome”) or systemic (pro-)inflammation also play important pathophysiological roles [7, 8]. It needs to be acknowledged that the unsatisfactory results of randomized clinical trials (RCTs) investigating short- to mid-term effects of different intravenous (i.v.) vasodilators or cardiac calcitropes adminis-

Address for correspondence: Prof. Ewa A. Jankowska, MD, PhD, FESC, FHFA, Institute of Heart Diseases, Wroclaw Medical University, ul. Borowska 213, 50-556 Wrocław, Poland, tel: +48 7173642 52, e-mail: ewa.jankowska@umw.edu.pl 
Table 1. Major large clinical trials investigating the impact of early pharmacological interventions in acute on "hard" clinical outcomes (morbidity and mortality).

\begin{tabular}{|c|c|c|c|}
\hline $\begin{array}{l}\text { Trial acronym, } \\
\text { year of publication } \\
\text { [reference number] }\end{array}$ & Population & $\begin{array}{l}\text { Intervention } \\
\text { and comparator }\end{array}$ & $\begin{array}{l}\text { Outcomes analyzed } \\
\text { and results }\end{array}$ \\
\hline $\begin{array}{l}\text { SURVIVE, } \\
2007 \text { [9] }\end{array}$ & $\begin{array}{l}1327 \text { patients hospitalized } \\
\text { with ADHF requiring } \\
\text { inotrope agents }\end{array}$ & $\begin{array}{l}\text { Levosimendan (inodilator/ } \\
\text { /cardiac calcitrope) } \\
\text { vs. dobutamine }\end{array}$ & $\begin{array}{l}\text { All-cause mortality } \\
\text { at } 180 \text { days; NS }\end{array}$ \\
\hline $\begin{array}{l}\text { ASCEND-HF, } \\
2011[10]\end{array}$ & $\begin{array}{l}7141 \text { patients } \\
\text { with AHF }\end{array}$ & $\begin{array}{l}\text { Nesiritide (vasodilator) } \\
\text { or placebo for } 24 \text { to } 168 \mathrm{~h}\end{array}$ & $\begin{array}{l}\text { Rate of re-hospitalization } \\
\text { for HF or death from any } \\
\text { cause within } 30 \text { days; NS }\end{array}$ \\
\hline $\begin{array}{l}\text { TRUE-AHF, } \\
2017[11]\end{array}$ & $\begin{array}{l}2157 \text { patients } \\
\text { with AHF }\end{array}$ & $\begin{array}{l}\text { Ularitide (vasodilator) } \\
\text { or placebo for } 48 \mathrm{~h}\end{array}$ & $\begin{array}{l}\text { CV death during a median } \\
\text { follow-up of } 15 \text { months; NS }\end{array}$ \\
\hline $\begin{array}{l}\text { RELAX-AHF-2, } \\
2019 \text { [12] }\end{array}$ & $\begin{array}{l}6545 \text { patients } \\
\text { with AHF }\end{array}$ & $\begin{array}{c}48 \mathrm{~h} \text { infusion of serelaxin } \\
\text { (vasodilator) or placebo } \\
\text { within } 16 \mathrm{~h} \text { after presentation }\end{array}$ & $\begin{array}{c}\text { Death from CV causes at } \\
180 \text { days; NS, and worsening } \\
\text { HF at } 5 \text { days; NS }\end{array}$ \\
\hline
\end{tabular}

AHF — acute heart failure; ADHF — acute decompensated heart failure; CV — cardiovascular; HF — heart failure; NS — not significant

tered in hospital to impact 'hard' clinical outcomes in AHF (Table 1) [9-12] have highlighted the need to search for other interventions than modulating cardiac inotropy, fluid (re-)distribution or vascular tone during the acute phase of the disease.

Indeed, available evidence from well-designed clinical trials in AHF implies that the concept of short but intensive support for cardiovascular hemodynamics presumably does not impact mid-to-long-term morbidity and mortality significantly in such patients. The only positive clinical trial in the broadly understood setting of AHF refers to subjects with acute decompensated heart failure (ADHF) and diabetes who were assigned early (before or shortly after discharge) to a chronic HF (CHF) drug sodium-glucose co-transporter 2 inhibitor (sotagliflozin) vs. placebo [13]. Therefore, there is still a need to test substances administered as a specific intervention for this acute state to improve outcomes. Moreover, it seems reasonable that a potential pharmaceutical should first act longer than in a hospital (ideally for weeks/ /months following one or a few easy administrations during the acute phase). Secondly, it is essential to target mechanisms involved in a complex AHF pathophysiology other than hemodynamics [14].

\section{Iron deficiency in the setting of acute} heart failure: Data from observational studies and evidence from clinical trials

Iron deficiency (ID), defined as reduced serum ferritin and/or transferrin saturation index (TSAT, serum iron divided by total iron-binding capacity), is highly prevalent in HF (in CHF it affects up to $50 \%$ patients) and worsens both symptoms and outcomes in these subjects independently of anemia [15-17]. There is evidence from multicenter, double-blind, RCTs (also aggregated in a few meta-analyses) that in patients with CHF with reduced to mid-range ejection fraction and concomitant ID (defined as serum ferritin $<100 \mu \mathrm{g} / \mathrm{L}$ or $100-299 \mu \mathrm{g} / \mathrm{L}$ if TSAT $<0.2)$ the administration of i.v. ferric carboxymaltose (FCM) improves exercise capacity, symptoms and the quality of life [18-21]. A few available observational studies investigating ID in patients hospitalized for AHF (Table 2) indicate that this comorbidity not only may even be more frequent in this clinical setting, but also iron status presents somewhat dynamics in AHF (Table 2) [16, 22-27].

Not surprisingly, ID in patients with AHF predicted increased mortality, greater risk for early unplanned readmission, and prolonged in-hospital stay. Although there were attempts to define ID more precisely and pathophysiology-oriented in AHF [16], most observational studies on the prevalence of ID in AHF used classical iron biomarkers implemented from $\mathrm{CHF}$ - serum ferritin and TSAT. Regarding i.v. iron therapy in patients hospitalized for AHF, data was limited until recently. In one small RCT PRACTICE-ASIA-HF conducted in two centers in Singapore yielding a total number of 50 patients hospitalized due to ADHF, there was a trend towards greater distance in 6-minute walking test distance over the 12-week study period in subjects given a single-dose FCM pre-discharge compared to placebo, and the drug was well-tolerated [28].

AFFIRM-AHF trial (NCT02937454) was designed to investigate the effects of i.v. FCM on 


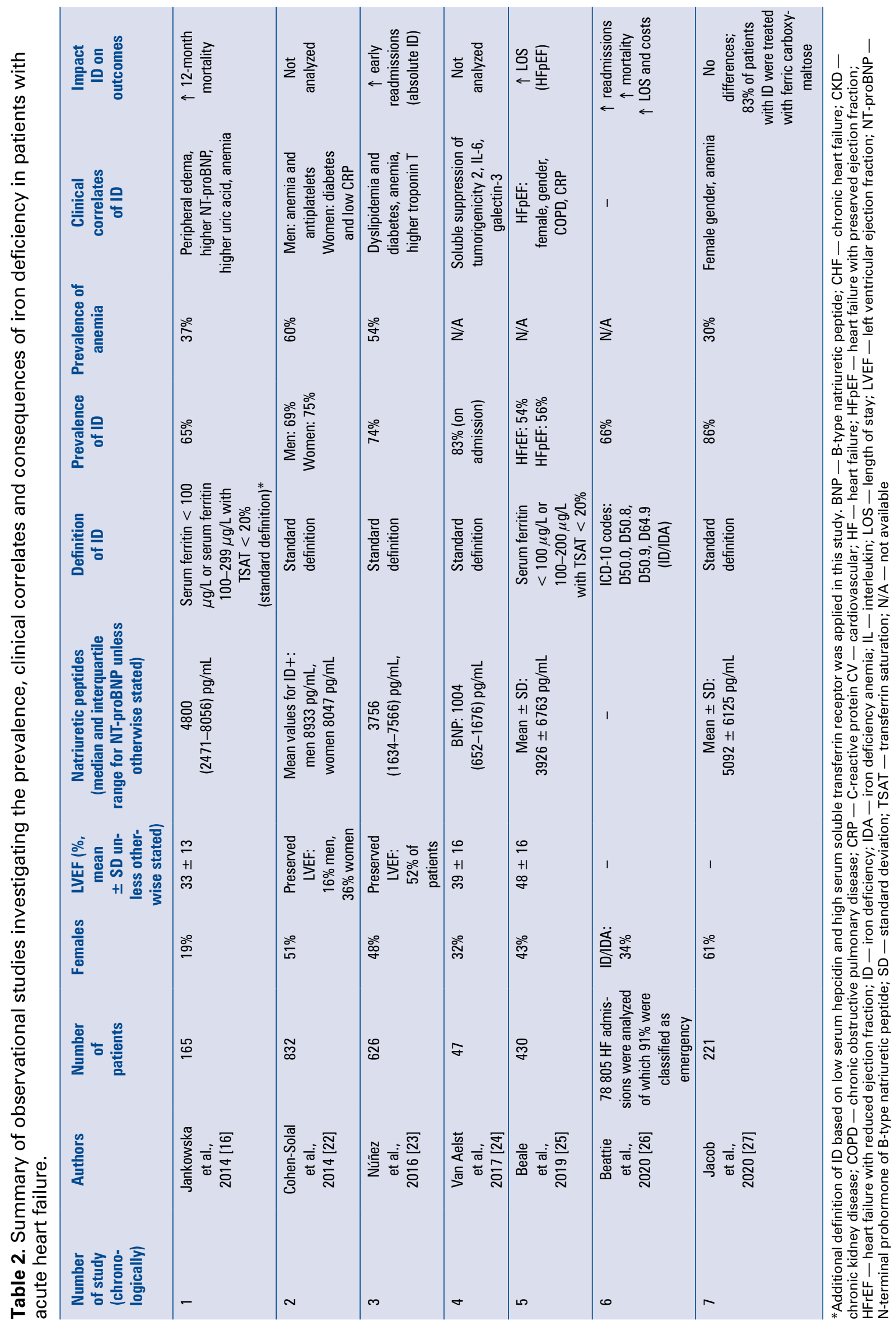




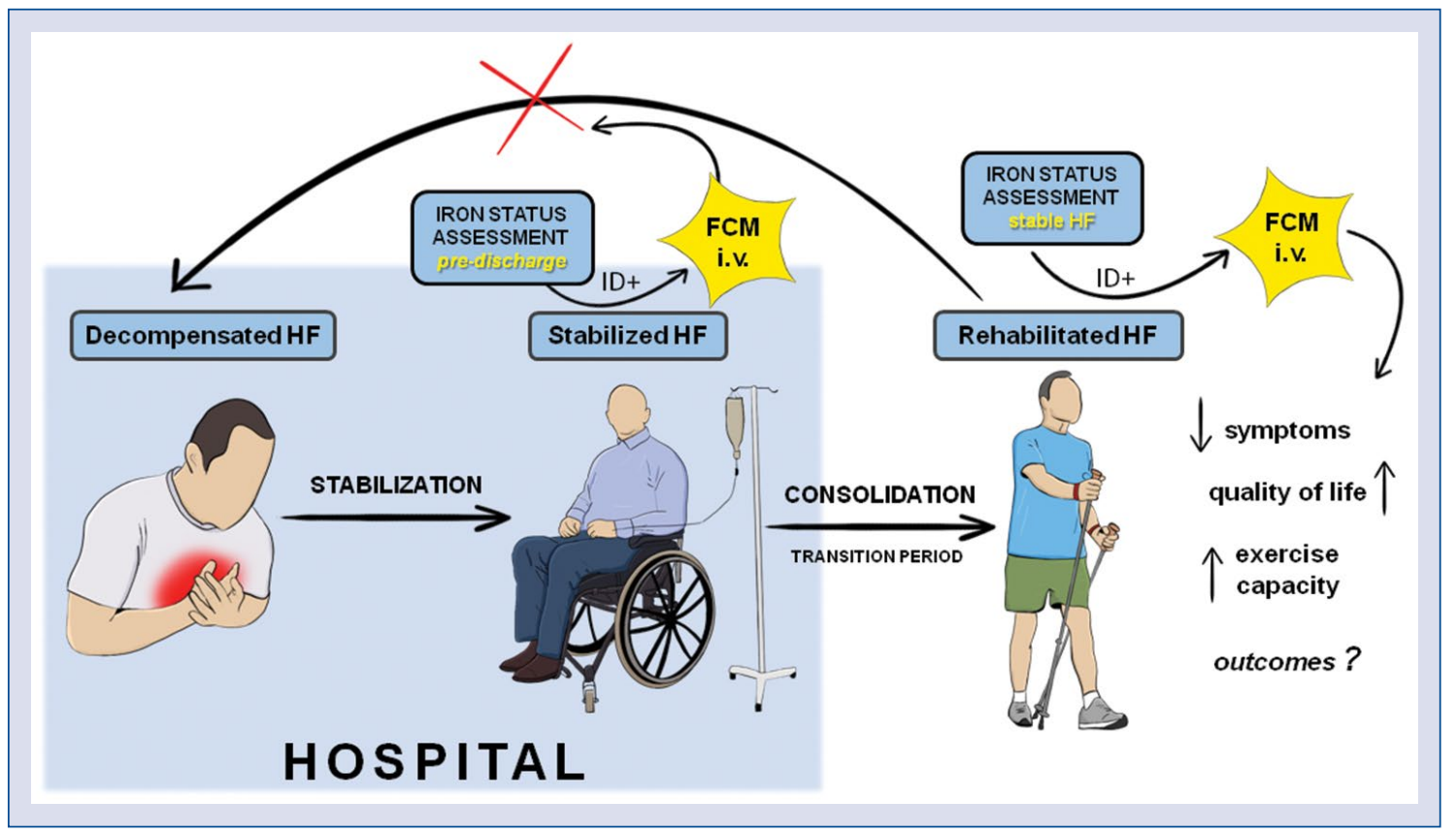

Central illustration. Positioning and beneficial effects of intravenous (i.v.) ferric carboxymaltose (FCM) therapy in patients with heart failure (HF) and iron deficiency (ID) based on published randomized clinical trials.

morbidity and mortality in iron-deficient patients hospitalized for AHF [29]. In this multicenter, multinational, double-blind RCT, more than 1100 patients aged $>18$ years who were hospitalized for AHF (with reduced or mildly reduced in-hospital left ventricular ejection fraction [LVEF], i.e. $<50 \%$ ) and had ID detected during index hospitalization (standard definition implemented from nephrology through RCTs in stable HF based on serum ferritin and TSAT) were randomized before hospital discharge (after achieving clinical stabilization) in a 1:1 proportion to receive i.v. FCM or placebo for up to 24 weeks (dosing based on ID severity) [30]. The primary outcome in the trial was a composite of total hospitalizations for HF and cardiovascular death up to 52 weeks. Although the primary endpoint did not reach the statistical significance (293 primary events in FCM arm vs. 372 in the placebo group with a rate ratio [RR] of $0.79,95 \%$ confidence interval [CI] 0.62-1.01, p = 0.059), there were fewer HF hospitalizations in an active treatment arm (217 total hospitalizations in FCM group vs. 294 in subjects assigned for placebo [RR 0.74; 95\% CI 0.58-0.94, $\mathrm{p}=0.013]$ ) [30]. Notably, such therapy resulted in clinically meaningful beneficial effects on health-related quality of life (assessed using Kansas City Cardiomyopathy Questionnaire) as early as 4 weeks after the first dose of iron, lasting up to week 24 [31]. Additionally, based on a modeling methodology, it has been estimated that FCM is homogeneously cost-effective in patients with AHF in different countries characterized by variant healthcare system design [32]. Based on the results of the AFFIRM-AHF trial in the recently published 2021 European Society of Cardiology Guidelines for the diagnosis and treatment of AHF and CHF [33], the indications for i.v. iron supplementation with FCM have been extended beyond stable, CHF. Namely, such therapy should be considered in symptomatic $\mathrm{HF}$ patients with LVEF $\leq 50 \%$ and ID (guidelines recommend the definition based on serum ferritin and TSAT - see above) and recently hospitalized for $\mathrm{HF}$ to improve symptoms and reduce the risk of $\mathrm{HF}$ hospitalization - as an element of peri-discharge management (class or recommendation IIa, level of evidence B) [33]. The guidelines also emphasize the need to actively screen for ID and anemia in all subjects with HF by clearly recommending the assessment of iron parameters (ferritin and TSAT as well as hemoglobin concentration/complete blood count) regularly (class of recommendation I, level of evidence C) [33].

\section{Acute heart failure and iron deficiency: Pathophysiological links}

The concept of modulating adverse clinical trajectories after an episode of acute HF (Cen- 
tral illustration) in terms of improving indices of morbidity and mortality by administering i.v. iron already in-hospital after clinical stabilization is based on a few (patho)physiological assumptions. There have also been discussions regarding, e.g., the appropriateness of the definition of ID in AHF borrowed from stable HF or the safety of such intense iron load in an acute setting.

Analogously to $\mathrm{CHF}$, the exact mechanisms of clinical benefits of i.v. iron (FCM) after an episode of AHF are not fully elucidated. The one hypothesized mechanism is linked with the energetic hypothesis of AHF. It emphasizes the critical involvement of iron in energy generation within all types of cells/tissues. Indeed, the chemical properties of iron warrant its crucial role in comprehensive cellular energetics through effective mitochondrial respiration [34]. Apart from oxygen transportation and storage as the constituent of hemoglobin and myoglobin, iron is an element of two key groups of proteins involved in cellular energy production - hemoproteins (e.g., cytochromes), and non-heme iron-containing proteins such as citric acid cycle enzyme aconitase [35, 36]. Just as stable HF is associated with a chronic cardiac energetic dysfunction and/ /or deficit, AHF is characterized by a rapid energetic imbalance within the myocardial muscle. Chronic (stable) HF has long been associated with energetic disturbances within the heart as a muscle that is undeniably energetically demanding $[37,38]$. The so-called "metabolic remodeling" of a chronically failing heart is visible functionally in terms of abnormal substrate utilization and impaired metabolism of high-energy phosphates and structurally through abnormal mitochondria that present with decreased biogenesis [39, 40]. For AHF, which is an acute and particularly dynamic process, less data is available, even experimental data. In one of the few available animal models of a pacing-induced decompensated HF, in dogs developing severe HF in this (patho)mechanism rapidly (within a few weeks), metabolic derangements were already observed in terms of substrate utilization shift in favor of glucose at the expense of free fatty acids [41]. Some information can also be obtained from hearts explanted during the orthotopic transplantation to treat refractory $\mathrm{HF}$ from life indications. The morpho-functional and energetic end-stage state of these organs reflects the acute phase of cardiac dysfunction in AHF/ADHF. For example, Leszek et al. [42] have demonstrated a notable reduction in left and right ventricular myocardial iron content in 33 explanted failing hearts compared to 11 non-failing organs.
Historically, depleted iron has been associated with anemia. However, experimental and clinical evidence shows that i.v. iron therapy in $\mathrm{HF}$ is about more than just elevating hemoglobin concentration. Moreover, this intervention exerts therapeutic effects longer than hours/days following its administration. It is worth noting that parenteral iron supplementation is simpler compared to infusion of vasoactive drugs/inotropes (requiring supervised and blood pressure-guided control of infusion in the setting of an acute cardiac care unit). Characteristics mentioned above of i.v. iron is known from clinical trials on FCM in stable $\mathrm{HF}$ with reduced ejection fraction (HFrEF) with concomitant ID. For example, in the CONFIRM$\mathrm{HF}$ trial demonstrating sustained beneficial effects of FCM on functional capacity in subjects with HFrEF and ID during the 1-year study period, as much as over $75 \%$ of patients assigned for FCM required only 1-2 administrations of the study drug at week 0 and optionally at week 6 [19]. Importantly, FCM brings clinical benefits in HF patients with concomitant ID regardless of anemia [21]. How i.v. iron improves functional capacity in HF has not been fully elucidated (oral does not work due to poly-etiological low absorption). We have proposed an explanation that i.v. iron could improve the functioning of skeletal muscles [43-45]. Charles-Edwards et al. [46] have demonstrated in an interventional study that in iron-deficient CHF patients, iron repletion indeed can improve skeletal muscle energetics (assessed in vivo using phosphorus magnetic resonance spectroscopy). Still, it is unknown whether such a mechanism may play a role in the myocardial muscle.

Until recently, it was not unequivocally clear if the CHF definition of ID would be appropriate for AHF patients (whose iron status is dynamic to some extent, as mentioned previously) in terms of differentiating potential beneficiaries of i.v. iron therapy group vs. subjects not requiring i.v. iron. There were also some doubts whether the definition of ID in AHF could be firmly based on serum ferritin, an acute phase reactant protein, and whether ferritin-guided referral for i.v. iron (the threshold for ID: < $100 \mu$ g per litre or $100-299$ with TSAT < 20\%) will be appropriate in AHF analogously to stable disease. The latter for cutoffs above were introduced based on nephrology expertise. Although not fully understood, hyperferritinemia in the course of inflammation (e.g. progressive bacterial infection leading to septic shock) is considered a protective mechanism through diverse immunomodulatory and anti-microbial effects [47]. 
There is no doubt that AHF is related to increased inflammatory processes within the organism. The roles of diverse circulating inflammatory biomarkers are still discussed for direct pathogenesis of acute myocardial dysfunction and the subsequent injury of other organs such as kidneys and lungs or liver [48]. The magnitude of systemic inflammation in the course of AHF is less expressed than, e.g., in sepsis. For example, in the sub-analysis of the ASCEND-HF trial investigating the effects of vasodilator nesiritide vs. placebo in more than 7 thousand patients hospitalized for AHF, it was demonstrated that high sensitivity $\mathrm{C}$-reactive protein is significantly increased within the first days of index hospitalization, followed by the general decline through the first month after admission (median concentrations for baseline, 48-72 h, and 30-day follow-up: 12.6, 11.0, and $4.7 \mathrm{mg} / \mathrm{L}$, respectively) [49]. Regardless of some doubts if CHF definition of ID will be valid for AHF subjects, another question arose if such therapy will be safe as in chronic, stable conditions. Cellular iron status is tightly controlled as cellular viability represents a U-shaped relationship with amounts of iron. Some authors express their doubts whether an intensive iron load is unequivocally safe in terms of potential overproduction of reactive oxygen species in particular tissues [50]. The results of the AFFIRM-AHF trial confirm the safety of FCM in patients hospitalized for AHF and add to our knowledge regarding clinical benefits of i.v. iron at different stages of the natural history of HF.

\section{Conclusions}

In the AFFIRM-AHF trial recruiting subjects with AHF and ID, there have been demonstrated treatment benefits of i.v. iron beyond what is known about the chronic stage of $\mathrm{HF}$, namely the administration of FCM vs. placebo initiated pre-discharge has been shown to reduce the risk of HF hospitalizations. The exact mechanisms of how intravenous iron improves outcomes in this clinical setting are not fully understood. Further translational research is needed to elucidate the acute and long-term myocardial vs. peripheral effects of such therapy. The results of sufficiently powered (to assess the impact on morbidity and mortality) RCTs on i.v. iron in chronic HF with ID is awaited.

Conflict of interest: Wroclaw Medical University received an unrestricted grant from Vifor Pharma. Michał Tkaczyszyn reports personal fees from V-Wave Ltd., Eidos Therapeutics, Cytokinetics,
Impulse Dynamics, outside the submitted work. Tomasz Skrzypczak and Jakub Michałowicz report no conflict of interest. Piotr Ponikowski reports grants, personal fees and other from Vifor Pharma; personal fees and other from Amgen, Bayer, Novartis, Abbott Vascular, Boehringer Ingelheim, Pfizer, Servier, AstraZeneca, Cibiem, BMS, Impulse Dynamics; personal fees from Berlin Chemie; and other from Cardiac Dimensions; outside the submitted work. Ewa A. Jankowska reports grants and personal fees from Vifor Pharma, Bayer, Novartis, Abbott, Boehringer Ingelheim, Pfizer, Servier, AstraZeneca, Berlin Chemie, Cardiac Dimensions, Takeda, Gedeon Richter, outside the submitted work. Both Piotr Ponikowski and Ewa A. Jankowska have been co-PIs in the AFFIRM-AHF trial sponsored by Vifor Pharma.

\section{References}

1. Krumholz HM, Parent EM, Tu N, et al. Readmission after hospitalization for congestive heart failure among Medicare beneficiaries. Arch Intern Med. 1997; 157(1): 99-104, indexed in Pubmed: 8996046.

2. Chioncel O, Mebazaa A, Maggioni AP, et al. Clinical phenotypes and outcome of patients hospitalized for acute heart failure: the ESC Heart Failure Long-Term Registry. Eur J Heart Fail. 2017; 19(10): 1242-1254, doi: 10.1002/ejhf.890, indexed in Pubmed: 28463462.

3. Dharmarajan K, Hsieh A, Lin Z, et al. Diagnoses and timing of 30-day readmissions after hospitalization for heart failure, acute myocardial infarction, or pneumonia. JAMA. 2013; 309(4): 355, doi: 10.1001/jama.2012.216476.

4. Tymińska A, Ozierański K, Grabowski M, et al. Feasibility of sacubitril/valsartan initiation early after acute decompensated heart failure. Cardiol J. 2020; 27(5): 625-632, doi: 10.5603/ CJ.a2020.0094, indexed in Pubmed: 32648251.

5. Jencks SF, Williams MV, Coleman EA. Rehospitalizations among patients in the Medicare fee-for-service program. $\mathrm{N}$ Engl J Med. 2009; 360(14): 1418-1428, doi: 10.1056/NEJMsa0803563, indexed in Pubmed: 19339721.

6. Yancy $\mathrm{CW}$. Acute heart failure: searching for a new evident truth. J Am Coll Cardiol. 2017; 69(11): 1420-1423, doi: 10.1016/j. jacc.2017.01.018, indexed in Pubmed: 28302293.

7. Cotter G, Felker GM, Adams KF, et al. The pathophysiology of acute heart failure--is it all about fluid accumulation? Am Heart J. 2008; 155(1): 9-18, doi: 10.1016/j.ahj.2006.02.038, indexed in Pubmed: 18082483.

8. Doehner W, Frenneaux M, Anker SD. Metabolic impairment in heart failure: the myocardial and systemic perspective. J Am Coll Cardiol. 2014; 64(13): 1388-1400, doi: 10.1016/j. jacc.2014.04.083, indexed in Pubmed: 25257642.

9. Mebazaa A, Nieminen MS, Packer M, et al. Levosimendan vs dobutamine for patients with acute decompensated heart failure: the SURVIVE Randomized Trial. JAMA. 2007; 297(17): 1883-1891, doi: 10.1001/jama.297.17.1883, indexed in Pubmed: 17473298.

10. O'Connor CM, Starling RC, Hernandez AF, et al. Effect of nesiritide in patients with acute decompensated heart failure. 
N Engl J Med. 2011; 365(1): 32-43, doi: 10.1056/NEJMoa1100171, indexed in Pubmed: 21732835.

11. Packer M, O'Connor C, McMurray JJV, et al. Effect of ularitide on cardiovascular mortality in acute heart failure. N Engl J Med. 2017; 376(20): 1956-1964, doi: 10.1056/NEJMoa1601895, indexed in Pubmed: 28402745.

12. Metra M, Teerlink JR, Cotter G, et al. Effects of serelaxin in patients with acute heart failure. N Engl J Med. 2019; 381(8): 716-726, doi: 10.1056/NEJMoa1801291, indexed in Pubmed: 31433919.

13. Bhatt D, Szarek M, Steg P, et al. Sotagliflozin in patients with diabetes and recent worsening heart failure. N Engl J Med. 2021; 384(2): 117-128, doi: 10.1056/nejmoa2030183.

14. Njoroge JN, Teerlink JR. Pathophysiology and therapeutic approaches to acute decompensated heart failure. Circ Res. 2021; 128(10): 1468-1486, doi: 10.1161/CIRCRESAHA.121.318186, indexed in Pubmed: 33983837.

15. Jankowska EA, Rozentryt P, Witkowska A, et al. Iron deficiency: an ominous sign in patients with systolic chronic heart failure. Eur Heart J. 2010; 31(15): 1872-1880, doi: 10.1093/eurheartj/ ehq158, indexed in Pubmed: 20570952.

16. Jankowska EA, Kasztura M, Sokolski M, et al. Iron deficiency defined as depleted iron stores accompanied by unmet cellular iron requirements identifies patients at the highest risk of death after an episode of acute heart failure. Eur Heart J. 2014; 35(36): 2468-2476, doi: 10.1093/eurheartj/ehu235, indexed in Pubmed: 24927731.

17. Klip IT, Comin-Colet J, Voors AA, et al. Iron deficiency in chronic heart failure: an international pooled analysis. Am Heart J. 2013; 165(4): 575-582.e3, doi: 10.1016/j.ahj.2013.01.017, indexed in Pubmed: 23537975

18. Anker SD, Comin Colet J, Filippatos G, et al. Ferric carboxymaltose in patients with heart failure and iron deficiency. $\mathrm{N}$ Engl J Med. 2009; 361(25): 2436-2448, doi: 10.1056/NEJMoa0908355, indexed in Pubmed: 19920054.

19. Ponikowski P, van Veldhuisen DJ, Comin-Colet J, et al. Beneficial effects of long-term intravenous iron therapy with ferric carboxymaltose in patients with symptomatic heart failure and iron deficiency†. Eur Heart J. 2015; 36(11): 657-668, doi: 10.1093/ eurhearti/ehu385, indexed in Pubmed: 25176939.

20. van Veldhuisen DJ, Ponikowski P, van der Meer P, et al. Effect of ferric carboxymaltose on exercise capacity in patients with chronic heart failure and iron deficiency. Circulation. 2017; 136(15): 1374-1383, doi: 10.1161/CIRCULATIONAHA.117.027497, indexed in Pubmed: 28701470.

21. Jankowska EA, Tkaczyszyn M, Suchocki T, et al. Effects of intravenous iron therapy in iron-deficient patients with systolic heart failure: a meta-analysis of randomized controlled trials. Eur J Heart Fail. 2016; 18(7): 786-795, doi: 10.1002/ejhf.473, indexed in Pubmed: 26821594.

22. Cohen-Solal A, Damy T, Terbah M, et al. High prevalence of iron deficiency in patients with acute decompensated heart failure. Eur J Heart Fail. 2014; 16(9): 984-991, doi: 10.1002/ejhf.139, indexed in Pubmed: 25065368.

23. Núñez J, García-Blas S, Comín-Colet J, et al. Iron deficiency and risk of early readmission following a hospitalization for acute heart failure. Eur J Heart Fail. 2016; 18(7): 798-802, doi: 10.1002/ejhf.513, indexed in Pubmed: 27030541.

24. Van Aelst LNL, Abraham M, Sadoune M, et al. Iron status and inflammatory biomarkers in patients with acutely decompensated heart failure: early in-hospital phase and 30-day follow-up.
Eur J Heart Fail. 2017; 19(8): 1075-1076, doi: 10.1002/ejhf.837, indexed in Pubmed: 28516737.

25. Beale A, Carballo D, Stirnemann J, et al. Iron deficiency in acute decompensated heart failure. J Clin Med. 2019; 8(10): 1569, doi: 10.3390/jcm8101569, indexed in Pubmed: 31581494.

26. Beattie JM, Khatib R, Phillips CJ, et al. Iron deficiency in 78805 people admitted with heart failure across England: a retrospective cohort study. Open Heart. 2020; 7(1): e001153, doi: 10.1136/ openhrt-2019-001153, indexed in Pubmed: 32201585.

27. Jacob J, Miró Ò, Ferre C, et al. Iron deficiency and safety of ferric carboxymaltose in patients with acute heart failure. AHF-ID study. Int J Clin Pract. 2020; 74(10): e13584, doi: 10.1111/ ijcp.13584, indexed in Pubmed: 32533907.

28. Yeo TJ, Yeo PS, Hadi FA, et al. Single-dose intravenous iron in Southeast Asian heart failure patients: a pilot randomized placebo-controlled study (PRACTICE-ASIA-HF). ESC Heart Fail. 2018; 5(2): 344-353, doi: 10.1002/ehf2.12250, indexed in Pubmed: 29345426.

29. Ponikowski P, Kirwan BA, Anker SD, et al. Rationale and design of the AFFIRM-AHF trial: a randomised, double-blind, placebocontrolled trial comparing the effect of intravenous ferric carboxymaltose on hospitalisations and mortality in iron-deficient patients admitted for acute heart failure. Eur J Heart Fail. 2019; 21(12): 1651-1658, doi: 10.1002/ejhf.1710, indexed in Pubmed: 31883356.

30. Ponikowski P, Kirwan BA, Anker SD, et al. Ferric carboxymaltose for iron deficiency at discharge after acute heart failure: a multicentre, double-blind, randomised, controlled trial. Lancet. 2020; 396(10266): 1895-1904, doi: 10.1016/S0140-6736(20)32339-4, indexed in Pubmed: 33197395.

31. Jankowska EA, Kirwan BA, Kosiborod M, et al. The effect of intravenous ferric carboxymaltose on health-related quality of life in iron-deficient patients with acute heart failure: the results of the AFFIRM-AHF study. Eur Heart J. 2021 [Epub ahead of print]: 3011-3020, doi: 10.1093/eurheartj/ehab234, indexed in Pubmed: 34080008.

32. McEwan P, Ponikowski P, Davis JA, et al. Ferric carboxymaltose for the treatment of iron deficiency in heart failure: a multinational cost-effectiveness analysis utilising AFFIRM-AHF. Eur J Heart Fail. 2021; 23(10): 1687-1697, doi: 10.1002/ejhf.2270, indexed in Pubmed: 34191394.

33. McDonagh TA, Metra M, Adamo M, et al. 2021 ESC Guidelines for the diagnosis and treatment of acute and chronic heart failure: Developed by the Task Force for the diagnosis and treatment of acute and chronic heart failure of the European Society of Cardiology (ESC) With the special contributio. Eur Heart J. 2021; 42(36): 3599726, doi: 10.1093/eurheartj/ehab368, indexed in Pubmed: 34447992.

34. Dev S, Babitt JL. Overview of iron metabolism in health and disease. Hemodial Int. 2017; 21 Suppl 1: S6-SS20, doi: 10.1111/ hdi.12542, indexed in Pubmed: 28296010.

35. Cairo CW, Mirchev R, Golan DE. Cytoskeletal regulation couples LFA-1 conformational changes to receptor lateral mobility and clustering. Immunity. 2006; 25(2): 297-308, doi: 10.1016/j.immuni.2006.06.012, indexed in Pubmed: 16901728.

36. Ponka P. Cell biology of heme. Am J Med Sci. 1999; 318(4): 241-256, doi: 10.1097/00000441-199910000-00004, indexed in Pubmed: 10522552.

37. Mettauer B, Zoll J, Garnier A, et al. Heart failure: a model of cardiac and skeletal muscle energetic failure. Pflugers Arch. 2006; 452(6): 653-666, doi: 10.1007/s00424-006-0072-7, indexed in Pubmed: 16767467. 
38. Neubauer S. The failing heart - an engine out of fuel. N Engl J Med. 2007; 356(11): 1140-1151, doi: 10.1056/NEJMra063052, indexed in Pubmed: 17360992.

39. Rosano GMc, Vitale C. Metabolic modulation of cardiac metabolism in heart failure. Card Fail Rev. 2018; 4(2): 99-103, doi: 10.15420/cfr.2018.18.2, indexed in Pubmed: 30206484.

40. Tuunanen H, Knuuti J. Metabolic remodelling in human heart failure. Cardiovasc Res. 2011; 90(2): 251-257, doi: 10.1093/cvr/ cvr052, indexed in Pubmed: 21372005.

41. Recchia FA, McConnell PI, Bernstein RD, et al. Reduced nitric oxide production and altered myocardial metabolism during the decompensation of pacing-induced heart failure in the conscious dog. Circ Res. 1998; 83(10): 969-979, doi: 10.1161/01. res.83.10.969, indexed in Pubmed: 9815144.

42. Leszek P, Sochanowicz B, Szperl M, et al. Myocardial iron homeostasis in advanced chronic heart failure patients. Int J Cardiol. 2012; 159(1): 47-52, doi: 10.1016/j.ijcard.2011.08.006, indexed in Pubmed: 21899903.

43. Tkaczyszyn M, Drozd M, Węgrzynowska-Teodorczyk K, et al. Depleted iron stores are associated with inspiratory muscle weakness independently of skeletal muscle mass in men with systolic chronic heart failure. J Cachexia Sarcopenia Muscle. 2018; 9(3): 547-556, doi: 10.1002/jcsm.12282, indexed in Pubmed: 29573220 .

44. Stugiewicz M, Tkaczyszyn M, Kasztura M, et al. The influence of iron deficiency on the functioning of skeletal muscles: ex- perimental evidence and clinical implications. Eur J Heart Fail. 2016; 18(7): 762-773, doi: 10.1002/ejhf.467, indexed in Pubmed: 26800032.

45. Tkaczyszyn M, Comín-Colet J, Voors AA, et al. Iron deficiency contributes to resistance to endogenous erythropoietin in anaemic heart failure patients. Eur J Heart Fail. 2021; 23(10): 1677-1686, doi: 10.1002/ejhf.2253, indexed in Pubmed: 34050579.

46. Charles-Edwards G, Amaral N, Sleigh A, et al. Effect of iron isomaltoside on skeletal muscle energetics in patients with chronic heart failure and iron deficiency. Circulation. 2019; 139(21): 2386-2398, doi: 10.1161/CIRCULATIONAHA.118.038516, indexed in Pubmed: 30776909.

47. Kernan KF, Carcillo JA. Hyperferritinemia and inflammation. Int Immunol. 2017; 29(9): 401-409, doi: 10.1093/intimm/dxx031, indexed in Pubmed: 28541437.

48. Murphy SP, Kakkar R, McCarthy CP, et al. Inflammation in Heart Failure: JACC State-of-the-Art Review. J Am Coll Cardiol. 2020; 75(11): 1324-1340, doi: 10.1016/j.jacc.2020.01.014, indexed in Pubmed: 32192660.

49. Kalogeropoulos AP, Tang WH, Hsu A, et al. High-sensitivity $\mathrm{C}$-reactive protein in acute heart failure: insights from the ASCEND-HF trial. J Card Fail. 2014; 20(5): 319-326, doi: 10.1016/j. cardfail.2014.02.002, indexed in Pubmed: 24530944.

50. Ghafourian K, Chang HC, Ardehali H. Intravenous iron therapy in heart failure: a different perspective. Eur J Heart Fail. 2019; 21(6): 703-714, doi: 10.1002/ejhf.1434, indexed in Pubmed: 30884037. 